\title{
ENTRE RIOS, RODOVIAS E GRANDES PROJETOS: MUDANÇAS E PERMANÊNCIAS EM REALIDADES URBANAS DO BAIXO TOCANTINS (PARÁ) $)^{*}$
}

\author{
Bruno Cezar Pereira Malheiro ${ }^{* *}$ \\ malheiro@ufpa.br \\ Saint-Clair Cordeiro da Trindade Júnior ${ }^{* * *}$ \\ stclair@ufpa.br
}

RESUMO: A reflexão acerca das mudanças e permanências das cidades ribeirinhas na Amazônia assume uma importância especial, pois permite analisar o perfil sócioespacial dessas cidades consideradas tradicionais, discutir parâmetros para pensar políticas de desenvolvimento para as mesmas, bem como problematizar o que seja nelas o direito à cidade. Neste sentido, cabe tomar o jogo entre as particularidades regionais e singularidades dessas cidades como ponto de partida para o exercício de um planejamento e de uma gestão que incorporem demandas locais específicas, considerando, em conseqüência, seus principais atributos sócio-espaciais. Para empreender essa discussão, buscamos levar em consideração as singularidades e particularidades das realidades sócio-espaciais de três cidades do Nordeste Paraense, a saber: Baião, Mocajuba e Cametá. Localizadas no Baixo Tocantins, tais cidades estão situadas entre dois grandes projetos econômicos, a Hidrelétrica de Tucuruí, no Município de Tucuruí, e o Complexo Albras-Alunorte, no Município de Barcarena. A partir de suas condições de cidades ribeirinhas tradicionais e das novas redes técnicas instaladas mais recentemente na sub-região da qual fazem parte, busca-se discutir os

\footnotetext{
* Pesquisa desenvolvida com o apoio financeiro da Fundação de Amparo à Pesquisa do Estado do Pará e da Fundação Ford por meio da FASE/Amazônia. Participaram da equipe os geógrafos José Carlos da Silva Cordovil e Maria Júlia Veiga da Silva; os bolsistas de iniciação científica Michel de Melo Lima e Romário Valente Santos, e os estagiários Bianca Pinho, Bruno Angelim do Rosário, Gleice Kelly Gonçalves da Costa e Isaias Farias.

** Mestre em Planejamento do Desenvolvimento pelo Núcleo de Altos Estudos Amazônicos da Universidade Federal do Pará. Professor da Universidade Federal do Pará -Campus de Marabá.

${ }^{* * *}$ Doutor em Geografia Humana pela Universidade de São Paulo. Professor da Faculdade de Geografia e Cartografia da Universidade Federal do Pará.
} 
processos de mudanças e permanências do ponto de vista socioespacial a elas relacionados.

PALAVRAS-CHAVE: Cidades Ribeirinhas, Baixo Tocantins, Cidades Híbridas, Rio, Rodovia.

\section{INTRODUÇÃO}

Uma prática muito comum em comunidades ribeirinhas da Amazônia, e em particular naquelas do Baixo Tocantins ${ }^{1}$, são as festas religiosas, para as quais muitos romeiros e festeiros chegam através dos rios. O leilão, um dos pontos altos da festa, revela um ritual por meio do qual as relações sociais locais se manifestam de forma marcante.

"O coração do santo", normalmente representado por um bolo, é disputado, em geral, por aqueles que são reconhecidos como notáveis dentro do contexto local. Trata-se de um donativo, considerado o principal, e que deve ser arrematado por aqueles que ofertarem o maior valor possível. Para além da contribuição financeira para a ordem religiosa ou para a paróquia local, simboliza, igualmente, uma espécie de manifestação de poder, que reflete a força e o confronto daqueles que, de alguma forma, possuem poder político, econômico e/ou simbólico.

Revelam-se ao nosso olhar as "cidades dos notáveis", que, segundo Santos (2003), vêm gradativamente sendo substituídas pelas "cidades econômicas", assimiladoras com maior força do modo de vida urbano relacionado, sobretudo, àquilo que o mesmo autor denominou de período técnico-científico-informacional. Diante da festa parece que esta afirmação deve ser relativizada!

Por outro lado, parece-nos coerente falar, como mostram Oliveira e Schor (2008), que, diferentemente do passado, quando a torre das igrejas eram os elementos que primeiro nos chamavam a atenção, agora são as antenas telefônicas os elementos que demarcam de imediato o contato da primeira vista ao se chegar a essas cidades tradicionais da Amazônia através dos grandes rios.

\footnotetext{
${ }^{1}$ A sub-região do Baixo Tocantins aqui considerada é formada por municípios localizados e/ou influenciados direta e indiretamente pela dinâmica do rio Tocantins, em seu baixo curso. Inclui. Dentre outros, os municípios de Limoeiro do Ajuru, de Cametá, de Igarapé Miri, de Mocajuba e de Baião.
} 
O "coração do santo" e a antena telefônica indicam, respectivamente, elementos de permanência e de mudança na vida dessas pequenas cidades. As festas e as antenas são metáforas que nos revelam uma problemática e indicam uma questão central para este artigo: que elementos concorrem para a permanência e para a alteração da vida local e da espacialidade associada às pequenas cidades ribeirinhas na Amazônia?

Para empreender essa discussão, tomaremos como referência três cidades do baixo curso de um grande rio, o Tocantins. Tratam-se das cidades de Baião e Mocajuba, situadas na sua margem direita, e de Cametá, situada na sua margem esquerda. Essas três cidades, localizadas na sub-região do Baixo Tocantins, no Estado do Pará, para além de estarem localizadas à margem desse grande rio, encontram-se situadas igualmente entre dois grandes projetos econômicos implantados na Amazônia nas últimas décadas do século XX: a Hidrelétrica de Tucuruí (produção de energia), no Município de Tucuruí, e o Complexo Albras-Alunorte (produção de alumina e alumínio), no Município de Barcarena.

Impactadas indiretamente pela implantação desses "grandes objetos" espaciais conforme propôs Santos (1995) para identificar os "grandes projetos" na Amazônia - e por outros elementos e processos que definem a modernização do espaço amazônico, essas cidades convivem permeadas pela tensão entre o novo e o herdado do passado, entre o que chega e altera e o que permanece.

Para nos aproximarmos dessas mudanças e permanências foi necessário, lançarmos mão de um reconhecimento da paisagem por meio de observação sistemática de campo e de um levantamento ${ }^{4}$ junto aos habitantes locais, o que nos permitiu uma primeira aproximação a respeito das mudanças e permanências sócioespaciais das cidades ribeirinhas, elementos de nossas preocupações.

\footnotetext{
${ }^{4}$ O levantamento foi feito por meio de formulários de campo aplicados em três bairros em cada uma das cidades consideradas, levando em conta a importância do rio para os habitantes locais. A amostragem dos bairros buscou considerar padrões diferentes de produção do espaço: a) o bairro ribeirinho, definido a partir da referência e da proximidade e/ou do maior contato com o rio; b) o bairro espontâneo /ou rodoviário, cujo padrão de ocupação prescinde da orientação ou da proximidade imediata do rio e tende a se definir tomando como referência elementos outros, como a rodovia, por exemplo; c) o bairro prédefinido, cujo padrão de ocupação é definido por meio de loteamentos e que, ainda que precários, definem um padrão de arruamento menos espontâneo e de caráter mais dirigido, em geral, pelo loteador responsável, que, na maioria das vezes, é o próprio poder público. Em cada um dos bairros, nas três cidades, foram aplicados de 80 (oitenta) a 100 (cem) formulários, de forma a abranger o conjunto de cada um deles.
} 
$\mathrm{O}$ argumento de nossa análise se estrutura da seguinte maneira. Inicialmente, buscamos mostrar os padrões de ordenamento intra-urbano nas cidades selecionadas para análise. Em seguida, apresentamos elementos relacionados à formação sócioespacial dessas realidades urbanas estudadas, discutindo aspectos vinculados à gênese histórica ribeirinha das mesmas, à formação sócio-espacial do passado e à nova dinâmica regional. Por fim, são apresentadas sistematizações dos levantamentos realizados, indicando elementos de permanência, de mudança e de convivência entre estas lógicas contraditórias nas três realidades observadas.

\section{OS PADRÕES DE ORDENAMENTO INTRA-URBANO EM BAIÃO, CAMETÁ E MOCAJUBA}

As cidades ribeirinhas na Amazônia não podem ser analisadas como formações urbanas que simplesmente estão à beira-rio, uma vez que a localização absoluta não é o único elemento definidor das mesmas. De igual maneira, elas não estão perdidas em um tempo passado e nem mesmo podem ser definidas simplesmente como contraponto às cidades à beira da estrada. Tratam-se, antes, de formações sócioespaciais em que o rio não define apenas os seus contornos físicos, mas está presente como meio de circulação, como referência para o imaginário, como meio de sobrevivência, sendo, assim, por onde navega a economia, a cultura, os símbolos, os ritos, a experiência social expressa nessas pequenas aglomerações urbanas.

Também podemos dizer que as cidades ribeirinhas dos notáveis não se animam somente pela notabilidade. Não é apenas uma correnteza que dá corpo a estas cidades, mas uma multiplicidade de trajetórias, de tempos, de ritmos. A cidade do rio também se anima pela estrada, o que nos faz vê-las não como resultados de um passado estático ou de um futuro avassalador, mas como um espaço-tempo presente, denso e vivo, cujos atributos maiores são a simultaneidade e a dinamicidade.

Esta simultaneidade e dinamicidade serão observadas aqui primeiramente no desenho intra-urbano dessas cidades para, posteriormente, buscarmos os elementos histórico-geográficos que explicam esse mesmo desenho.

De modo geral, de acordo com Trindade Jr., Silva e Amaral (2008) podem ser reconhecidos três padrões distintos na estrutura intra-urbana das cidades ribeirinhas. 
O primeiro padrão é o ribeirinho, que apresenta um ordenamento não aleatório, uma vez ser definido e direcionado pelo rio; o segundo padrão é o "espontâneo" que não se define a partir de orientação referencial da via fluvial, mas é construído aleatoriamente de acordo com interesses - em geral o de necessidade de moradia - de apropriação do espaço dos diversos agentes; o terceiro padrão é o pré-definido ou dirigido, que reflete o processo de apropriação do espaço direcionado pelo Estado ou pela iniciativa privada, na forma de loteamentos públicos e privados. Acrescentaríamos a esses padrões o rodoviário, no qual a dinâmica de apropriação do espaço se liga direta ou indiretamente aos processos relacionados à circulação rodoviária, sendo, portanto, definido e direcionado pelas estradas principais ou vicinais.

Vale dizer que, embora estejamos dando o nome de padrão a estes processos diferenciados de apropriação do espaço, não podemos observá-los de maneira estanque e sem relação, nem identificar áreas perfeitamente homogêneas onde apenas um padrão seja observado. A cidade em si, como sustenta Lefebvre (2001), reflete a coexistência de padrões, de maneiras de uso do espaço e de tempos diferentes, mas contraditoriamente articulados.

A partir desta constatação definimos procedimentos de levantamento de campo nas três cidades (Baião, Cametá e Mocajuba) estudadas, com a aplicação de formulários de campo em três bairros em cada cidade em específico. A escolha dos bairros se deu da seguinte forma: o primeiro bairro escolhido deveria refletir o padrão ribeirinho, o segundo deveria ter característica mista dos padrões aleatório e rodoviário e um terceiro bairro deveria ter-se formado a partir do padrão dirigido. Essa escolha nos deu a possibilidade de chegar a dados mais confiáveis da cidade como um todo no sentido de compreender melhor suas mudanças e permanências.

Para a cidade de Cametá foram escolhidos os bairros do Centro, que se organiza a partir de um padrão ribeirinho, o bairro de Nova Cametá, que apresenta característica mista dos padrões aleatório e rodoviário, e o bairro Primavera, que é formado a partir de um padrão dirigido. O mesmo aconteceu nas outras cidades, sendo em Baião escolhidos os bairros do Centro (ribeirinho), Marambaia (aleatório e rodoviário) e Pilar/Bairro Novo (dirigidos). Em Mocajuba, foram selecionados os 
bairros do Centro (ribeirinho), Campina (aleatório e rodoviário) e Cidade Nova (dirigido). Em cada bairro foram aplicados formulários em estabelecimentos residenciais obedecendo a um padrão estatístico minimamente confiável em termos de amostragem, conforme já mencionado anteriormente.

Constatamos, em linhas gerais, que os processos distintos observados na constituição histórica dessas cidades ganham corpo em paisagens diferenciadas, sendo os padrões reconhecidos a síntese dos múltiplos tempos que animam a produção do espaço nesses aglomerados urbanos, quase como um desenho intra-urbano de temporalidades múltiplas, que hoje se apresentam contraditoriamente articuladas.

Nesse sentido, a partir da visualização desse desenho de múltiplas temporalidades, faz-se necessário, a partir de agora, compreender a maneira como as cidades aqui analisadas se organizaram ao longo da história, visualizando momentos em que o rio é o direcionador da ocupação urbana e momentos em que esse papel é relativizado a partir da expansão das estradas e de outros sistemas de objetos tecnicamente mais avançados.

DA SUCESSÃO À COEXISTÊNCIA: O BAIXO TOCANTINS ENTRE O RIO, A ESTRADA E OS GRANDES PROJETOS

Conforme já mencionamos, as cidades de Baião, Cametá e Mocajuba se localizam no baixo curso do rio Tocantins e apresentam uma história de formação que mostra que o rio é elemento central na definição da vida econômica, social e cultural das mesmas, o que demonstra uma grande ligação dessas cidades com seu entorno imediato. A escolha das três realidades para análise se justifica por essa forte sociabilidade, forte ligação material e simbólica constituída ao longo da história.

Durante o período colonial a região do Baixo Tocantins se mostrou como importante vetor de expansão da fé católica a partir da formação de aldeamentos indígenas. Temos, nesse momento, um destaque especial para a formação do núcleo Cametá-Tapera fundado em 1620 pela ordem dos franciscanos, mas que depois ficou sob o domínio dos jesuítas para a administração dos padres da Piedade e, também, a 
fundação do núcleo de Baião a partir da sesmaria concedida por Antônio de Albuquerque Carvalho a Antônio Baião (BAIÃO, 1979).

Nesse momento, é importante lembrar, a região sofreu um processo de colonização marcado não só pela força político-administrativa e militar do Estado português, mas também estruturado pelas ordens religiosas com a ocupação dispersa da floresta através da atividade da coleta das drogas do sertão que era feita, em sua maioria, por índios dominados e destribalizados.

Em meados do século XVIII aquela forma de ordenamento e ocupação do território empreendida no século XVII foi profundamente modificada com a política do Marquez de Pombal para a região amazônica. Em termos gerais, a política pombalina promoveu o estabelecimento de uma separação entre o Estado e a Igreja, fato este que culminou com a expulsão, em 1769, dos jesuítas da região; concedeu liberdade aos índios; estruturou uma política de incentivo à agricultura e à pecuária; institucionalizou a mão-de-obra negra africana na região; ofereceu condição para a criação de povoados e elevou 40 (quarenta) aldeias à categoria de vilas; construiu fortificações em áreas estratégicas; promoveu uma reforma no ensino até então a cargo dos jesuítas; e, particularmente na Amazônia, também promoveu uma "revolução" urbana principalmente com a vinda do arquiteto italiano Antônio Landi, que passou a assinar vários projetos arquitetônicos na região, inclusive o da igreja matriz de Cametá (GONÇALVES, 2002).

Nesse momento observamos no Baixo Tocantins um reforço do povoamento ao longo dos rios, além da transformação das aldeias missionárias em vilas e freguesias; o que acontece, por exemplo, com Baião, em 1758. É relevante observar, também, o significado das lavouras de cacau nessa região e a grande importância assumida por Cametá nas funções de comércio e serviços no contexto amazônico.

Mas, para além da história oficial, outros atores se mostram como fundamentais para o processo de ocupação do Baixo Tocantins. São eles os índios fugidos das missões e embrenhados na floresta, responsáveis pela formação de múltiplas aldeias; os negros fugidos que formaram vários quilombos em locais de difícil acesso e que existem até hoje, a exemplo do que revela o Centro de Cartografia e 
Informação Geográfica (GICA) da Universidade de Brasília (O LIBERAL, 2005), que reconhece 32 (trinta e duas) comunidades quilombolas em Baião, 12 (doze) em Cametá e de 1 (uma) em Mocajuba; além das comunidades ribeirinhas também responsáveis pelo processo de ocupação e gênese das cidades e povoados às margens do Tocantins.

No quadro social amazônico percebia-se uma intensa desintegração indígena resultante de mais de um século de sujeição dos índios à igreja, sendo que após a expulsão dos jesuítas da região criou-se, ainda, uma série de dificuldades de subordinação desses índios ao Estado, pela falta de novas práticas de controle. Esse quadro, aliado à constituição de uma sociedade de caboclos, aos quais se negava o direito de cidadania, constituíram-se, segundo Di Paolo (1985), as causas remotas do movimento cabano, que também teve suas causas próximas ${ }^{3}$.

A cidade de Cametá foi núcleo de resistência ao movimento cabano entre 1835-1940 e, inclusive, sede da resistência legalista e capital da província por alguns dias. Se Cametá apresenta-se como foco da resistência legalista, percebemos, por outro lado, que Baião, mesmo após a expulsão dos cabanos de Belém, em 1836, permaneceu sob o domínio cabano e foi um importante núcleo para organização e difusão do movimento. A descrição que segue é interessante para melhor compreendermos esse momento da história regional:

Estendeu-se a Revolta dos Cabanos a todas as áreas da região o que reduziu ainda mais a escassa população da Amazônia, restringiu a atividade coletora de produtos do sertão, arruinou currais de gado e fazenda de lavoura, e fez minguar o povoamento de certas zonas pelo abandono de numerosas povoações [...]. Em maio de 1836 os cabanos foram obrigados a abandonar a capital, mais já dominavam as povoações da costa oriental, as das áreas dos rios Guamá e Moju, a ilha do Marajó, as povoações de Baião (no Tocantins), Monte Alegre,

\footnotetext{
${ }^{3}$ Dentre as causas próximas temos o golpe militar de 1 de março de 1823 que colocou no poder da província do Pará o Partido Português; o assassinato público dos Mártires do Largo do Palácio e a humilhação de Batista Campos, também em 1923, feita por Greenfell; o episódio do brigue "Palhaço" em 17 de outubro de 1823 que culminou na morte de 252 paraenses; o bombardeio de Cametá ocorrido como protesto português a primeira vila a aderir à Independência; o golpe institucional de junho de 1831, quando o presidente Burgos impede a posse do então vice-presidente Batista Campos; além de vários acontecimentos mais imediatos que contribuíram para o início da insurreição, como a prisão de Eduardo Angelim em 1834, o incêndio da fazenda de Félix Antônio Clemente Malcher, além da ameaça de morte feita pelo presidente da Província do Pará nesse momento, Lobo de Souza, à Batista Campos e a posterior morte de Campos após uma perseguição policial (DI PAOLO, 1985).
} 
Óbidos e Santarém (nas margens do Amazônas). Foram dominados por completo só no decorrer de 1839 e 1840 (SILVA BRUNO, 1966, p. 97).

Após o desmanche do movimento cabano, depois de violenta repressão, os principais produtos exportados pelo Pará eram o fumo, o cacau, o couro e a borracha, sendo que este último produto começava a ganhar grandes proporções nas exportações e a despertar, por sua vez, opiniões diversas das elites estabelecidas na região.

As elites regionais ligadas à agricultura, além da elite política do Pará, não viam com bons olhos a expansão da atividade extrativa da borracha, mesmo ganhando este produto uma grande importância para as exportações da Província:

Ao contrário que habitualmente se supõe, muitos grupos da elite paraense demonstravam surpreendente relutância, ou até mesmo aversão, em relação ao desenvolvimento da mais importante exportação da província [a borracha]. E isso é particularmente interessante, se se considerar que a maioria dos brasileiros no século XIX ainda encarava a prosperidade e o crescimento econômico como intimamente vinculados à expansão do setor exportador (WEINSTEIN, 1993, p. 55).

Porém, apesar dessas contradições, já na década de 1850 a borracha se colocava como principal produto do comércio regional. Vivenciava-se, nesse contexto, um importante momento da produção do espaço regional, que se inscreve temporalmente da segunda metade do século XIX ao início do século posterior e é marcado por grandes transformações da região.

O Baixo Tocantins nesse contexto assumiu pouco destaque e a cidade de Cametá perdeu importância frente a outros centros mais inseridos na produção e no comércio da borracha, como Santarém. Este pequeno destaque se deve a dois motivos, o primeiro relacionado à perda da importância do cacau na economia da Província e o segundo está relacionado à rápida exaustão dos seringais da região em função da utilização do seringal caboclo (CORRÊA, 1992).

O início do século XX é marcado pelo arrefecimento da economia da borracha em conseqüência da concorrência dos seringais do sudeste asiático, estagnação esta que 
se reflete no Baixo Tocantins, onde se desenvolve, em algumas localidades, a produção da juta e da malva e a circulação da castanha-do-pará. Esta estagnação provocou um enfraquecimento do poder estatal e conseqüentemente o fortalecimento das oligarquias, a exemplo dos Mendonça em Cametá (POMPEU, 2002).

Após essa estagnação os acontecimentos e conflitos da Segunda Guerra mundial colocaram novamente a Amazônia como principal centro fornecedor de borracha, fato que gerou um novo crescimento econômico na região de forma rápida e sem grandes conseqüências para o baixo curso do rio Tocantins.

A partir de meados dos anos de 1940 e décadas posteriores, a Amazônia tornouse definitivamente uma questão nacional e a Carta de 1946 é reflexo disso, pois aponta os pressupostos básicos de um planejamento regional coordenado pela política nacional. É pensada, nesse contexto, a criação da Superintendência de Valorização Econômica da Amazônia (SPVEA), que no primeiro plano qüinqüenal previa o investimento em transporte, comunicação e energia, além do desenvolvimento agrícola e da industrialização de matérias-prima (D'ARAÚJO, 1992).

Os militares consolidam este esboço atrelando aos ideais de integrar, ocupar e desenvolver o território, a doutrina de segurança nacional, o que é concretizado no I e no II Plano de Desenvolvimento da Amazônia (PDA) e na criação da Superintendência de Desenvolvimento da Amazônia (SUDAM). O I PDA objetivava a integração física, econômica e cultural da Amazônia ao Centro-Sul do Brasil, além de ocupar o território e promover o desenvolvimento econômico. Por outro lado, no II PDA já se mostrava mais clara a idéia de um desenvolvimento via industrialização com investimentos massivos em transporte e energia, a partir, por exemplo, da formulação do POLAMAZÔNIA (Programa de Pólos Agropecuários e Agrominerais da Amazônia), que visava à implantação de 15 pólos de desenvolvimento regional a partir da instalação de grandes projetos na Amazônia oriental voltados, sobretudo, à exploração mineral e articulados pelo Programa Grande Carajás (PGC) (BRITO, 2001).

É a partir desse contexto que passam a se instalar os "grandes objetos" ao longo do curso do rio Tocantins conformando uma nova lógica econômica para esta região. A Usina Hidrelétrica de Tucuruí (UHT) e o complexo Albras-Alunorte serão a expressão 
do PGC no vale daquele rio, o primeiro no seu médio curso e o segundo nas proximidades de sua foz. A UHT foi um empreendimento criado para abastecimento de energia de grandes centros urbanos regionais e também para a própria AlbrasAlunorte, que beneficia a bauxita vinda das minas de Oriximiná $(\mathrm{Pa})$, transformando-a em alumina e, posteriormente, em alumínio. Vale dizer, que, além da UHT, para dar suporte a Albras-Alunorte também foram criados: o Porto de Vila do Conde, a cidadeempresa (Vila dos Cabanos), bem como um sistema rodoviário.

Esse processo de expansão capitalista na Amazônia altera padrões de organização do espaço no Baixo Tocantins a partir da construção da Usina Hidrelétrica de Tucuruí que foi planejada para ser concluída em duas etapas, a primeira (19791992) quando foram instaladas 12 unidades geradoras principais com duas auxiliares e a segunda que se iniciou em 1998 e prevê a construção de mais 11 unidades.

Embora os impactos ambientais e sociais tenham vindo imediatamente após a construção da Usina, a energia desta mesma usina só chegou às cidades de Cametá, Baião e Mocajuba no final da década de 1990 com a expansão do linhão no Baixo Tocantins.

Afora a energia elétrica, outras redes técnicas forma instaladas nessa sub-região, como a de telecomunicações, através da TV e a de telefonia fixa e móvel. Não se pode deixar de mencionar, igualmente, os novos eixos de circulação intra-regional criados, os quais se ligam a um novo padrão de ocupação espacial cuja referência não é mais o rio, mas a estrada. É nesse contexto que visualizamos a construção/melhoramento/pavimentação de algumas estradas estaduais, como a PA150, que liga Moju a Redenção, a PA - 151 que vai do porto do Arapari, em Barcarena, até Baião, passando por Abaetetuba, Igarapé Miri, Cametá e Mocajuba, além da Transcametá (PA-156) que liga Tucuruí a Limoeiro do Ajuru.

Esse contexto de relações capitalistas incentiva, na realidade analisada, muito mais que uma urbanização da população (tabela 1), que se define pelo incremento da população urbana vivendo nas cidades e vilas, uma mudança no conteúdo material do território, relacionada ao que Santos (2004) denominou de tecnosfera, e que nos remete à instalação de novos sistemas de engenharia na região, acompanhando as 
redes técnicas instaladas, como a viária e a elétrica. Atrelada aos processos anteriormente visualizados, percebemos a proliferação significativa, principalmente com a expansão das redes de telecomunicação, no nosso caso em específico na subregião do Baixo Tocantins, daquilo que Santos (2004) chamou de psicosfera urbana que, por sua vez, traduz-se na difusão de um sistema de valores guiados por uma racionalidade hegemônica urbana.

TABELA 1 - POPULAÇÂO DO BAIXO TOCANTINS SEGUNDO O LOCAL DE DOMICÍLIO - 2004

\begin{tabular}{l|r|r|r|}
\hline MUNICÍPIO & $\begin{array}{c}\text { POPULAÇÃO } \\
\text { TOTAL }\end{array}$ & $\begin{array}{c}\text { POPULAÇÃO FORA DA SEDE } \\
\text { MUNICIPAL }\end{array}$ & $\begin{array}{c}\text { POPULAÇÃO NA SEDE } \\
\text { MUNICIPAL }\end{array}$ \\
\hline Baião & 21.673 & 10.523 & 11.150 \\
\hline Cametá & 104.210 & 61.066 & 43.144 \\
\hline Mocajuba & 21.626 & 6.297 & 15.329 \\
\hline
\end{tabular}
Fonte: GOVERNO DO PARÁ. Secretaria de Estado de Planejamento, Orçamento e Finanças (SEPOF-PA),
2006.

Nesses termos a sub-região do Baixo Tocantins emerge para análise como uma realidade sócio-espacial múltipla, inserida em uma dinâmica de fronteira que apresenta uma situação de conflito social, sendo, assim, essencialmente o lugar da alteridade, do (des)encontro de perspectivas que denotam tempos históricos diferenciados, ainda que contemporâneos (MARTINS, 1997).

O RIO, OS BARCOS, OS PORTOS E A FEIRA: PERMANÊNCIAS...

Para começar a falar das permanências de uma dinâmica ribeirinha nas cidades de Baião, Cametá e Mocajuba é necessário começar pelos tempos que apresentam uma longa duração, estruturando até hoje relações sociais e animando a dinâmica de produção do espaço.

A história dessas cidades parece contar uma grande influência católica. A igreja sempre teve uma importância singular, seja nos processos de fundação das mesmas, seja na vida comercial, ou, ainda, no desenho dos valores dos sujeitos. Esse tempo, que é social e espacial, uma vez ser difundido a partir de um centro forjado (a Europa), 
parece se incorporar à vida dessas cidades a partir de suas singularidades, ganhando corpo, por exemplo, na definição de um modo de vida permeado pela notabilidade.

Esse tempo parece, ainda, ser reforçado mesmo após a expulsão dos jesuítas com a política pombalina para a Amazônia e o incentivo à racionalização das atividades econômicas, uma vez que essa política vai promover a emergência de oligarquias, as quais se fortalecem no início do século $X X$ a partir do contexto de estagnação econômica regional e enfraquecimento do poder político do Estado. A cidade dos notáveis é, assim, a expressão desse tempo de longa duração que, mesmo diante do imperativo econômico colocado para a região a partir principalmente de 1960, não se deixa diluir completamente pela racionalidade do capital, pois ainda encontra-se impregnado na forma de interação simbólica dos sujeitos. Que digam as festas de santo...!

Outro tempo de longa duração que permanece é o tempo do rio, que não é apenas natural e expresso pelas enchentes e vazantes, é social e espacial, uma vez que está presente como estruturador do cotidiano de múltiplos sujeitos e ser ainda definidor de espaços de reprodução de sua dinâmica. A tabela 2 demonstra que nas três cidades analisadas o rio ainda é um elemento de grande importância.

TABELA 2 - IMPORTÂNCIA DO RIO

\begin{tabular}{|l|r|r|r|r|r|r|r|r|}
\hline & \multicolumn{2}{|c|}{ Baião } & \multicolumn{2}{|c|}{ Mocajuba } & \multicolumn{2}{c|}{ Cametá } & \multicolumn{2}{c|}{ Média } \\
\hline Importância do rio & Abs. & \multicolumn{1}{|c|}{$\%$} & Abs. & \multicolumn{1}{c|}{$\%$} & Abs. & \multicolumn{1}{c|}{$\%$} & $\mathbf{1}$ \\
\hline Via de transporte & 24 & 9,28 & 51 & 19,95 & 44 & 16,92 & $\mathbf{4 6 , 3 9}$ \\
\hline Fonte de recursos & $\mathbf{1 0 0}$ & $\mathbf{3 9 , 8 3}$ & $\mathbf{1 6 8}$ & $\mathbf{6 3 , 9 2}$ & $\mathbf{8 7}$ & $\mathbf{3 5 , 4 2}$ & $\mathbf{7}, 36$ \\
\hline Espaço de lazer & 20 & 8,00 & 23 & 8,83 & 13 & 5,25 & 0,14 \\
\hline Uso doméstico & 0 & 0,00 & 1 & 0,42 & 0 & 0,00 & 2,44 \\
\hline Espaço de contemplação & 3 & 1,25 & 11 & 4,50 & 4 & 1,58 & 0,28 \\
\hline $\begin{array}{l}\text { Espaços de manifestações } \\
\text { culturais/religiosas }\end{array}$ & 0 & 0,00 & 2 & 0,83 & 0 & 0,00 & 26,39 \\
\hline $\begin{array}{l}\text { Transporte/recursos/lazer/ } \\
\text { Contemplação }\end{array}$ & 109 & 40,17 & 0 & 0,00 & 107 & 39,00 & 0,47 \\
\hline Não opinaram & 0 & 0,00 & 0 & 0,00 & 4 & 1,42 & 1,17 \\
\hline Não tem importância & 4 & 1,50 & 4 & 1,58 & 1 & 0,42 & $\mathbf{1 0 0 , 0 0}$ \\
\hline Total & $\mathbf{2 6 0}$ & $\mathbf{1 0 0 , 0 0}$ & $\mathbf{2 6 0}$ & $\mathbf{1 0 0 , 0 0}$ & $\mathbf{2 6 0}$ & $\mathbf{1 0 0 , 0 0}$ & \\
\hline
\end{tabular}

Fonte: Trabalho de campo, outubro/2008.

Se formos observar de maneira mais atenta os dados, perceberemos que, na média das três cidades, apenas $1,17 \%$ dos sujeitos afirmam que o rio não tem 
importância, enquanto $98,36 \%$ dos sujeitos ainda afirmam que o rio é importante. Essa importância é devida principalmente ao fato de ser o rio fonte de recursos para estes sujeitos e, ainda, via de transporte e espaço de lazer e contemplação.

Os objetos/símbolos dessa temporalidade ribeirinha são: o próprio rio, os barcos, os portos e a feira. O rio aparece, então, enquanto espelho do movimento, como definidor de cotidianos e de itinerários com seus regimes de enchente e vazante; os barcos servem de elo entre as comunidades ribeirinhas, comunidades quilombolas, dentre outras, e a cidade, e vice-versa; os portos são os pontos de encontro da cidade com o rio, do cosmos citadino e ribeirinho, das mercadorias vindas do rio e das que saem da cidade por ele; e a feira é o lugar onde se horizontalizam as relações, onde se trocam as mercadorias e, ao mesmo tempo, as conversas, onde se desenvolvem as experiências, onde se narram as estórias...

Se analisarmos os dados coletados durante os trabalhos de campo vamos perceber que nas três cidades uma das principais motivações para o uso da beira do rio, seguindo a motivação do lazer, é a compra de produtos na feira, cerca de $27,16 \%$ na média dos sujeitos ouvidos nas três cidades indicam que usam as orlas fluviais de suas cidades para fazerem compras e isso se realiza quase sempre na feira.

TABELA 3 - MOTIVAÇÃO DO USO DA BEIRA-RIO

\begin{tabular}{|c|c|c|c|c|c|c|c|}
\hline \multirow{2}{*}{$\begin{array}{l}\text { Motivação do uso da } \\
\text { beira-rio }\end{array}$} & \multicolumn{2}{|c|}{ Baião } & \multicolumn{2}{|c|}{ Cametá } & \multicolumn{2}{|c|}{ Mocajuba } & \multirow{2}{*}{$\frac{\text { Média }}{\%}$} \\
\hline & Abs. & $\%$ & Abs. & $\%$ & Abs. & $\%$ & \\
\hline Lazer & 90 & 34,62 & 98 & 37,69 & 72 & 27,72 & 33,34 \\
\hline Compras & 53 & 20,38 & 52 & 20,01 & 106 & 40,77 & 27,05 \\
\hline Uso do transporte fluvial & 23 & 8,85 & 6 & 2,31 & 17 & 6,54 & 5,90 \\
\hline Contemplação do rio & 3 & 1,15 & 8 & 3,08 & 12 & 4,60 & 2,94 \\
\hline Trabalho & 5 & 1,92 & 5 & 1,92 & 44 & 16,92 & 6,92 \\
\hline Uso doméstico & 0,00 & 0,00 & 1 & 0,38 & 6 & 2,30 & 0,89 \\
\hline $\begin{array}{l}\text { Lazer/compras/trans- } \\
\text { porte/contemplação }\end{array}$ & 76 & 29,23 & 81 & 31,15 & - & - & 20,13 \\
\hline Não vai & 10 & 3,85 & 8 & 3,08 & - & - & 2,31 \\
\hline Outros & - & - & 1 & 0,38 & 3 & 1,15 & 0,51 \\
\hline Total & 260 & 100 & 260 & 100 & 260 & 100 & 100 \\
\hline
\end{tabular}

Fonte: Trabalho de campo, outubro/2008. 
Não são apenas sujeitos vindos do rio que trazem seus produtos que animam o comércio nas feiras, os agricultores de vários assentamentos nas margens das estradas trazem também seus produtos para a feira. Do artesanato local aos produtos importados, do açaí à cachaça, do peixe fresco às sardinhas em lata, a feira se mostra como o lugar do encontro de distintas lógicas econômicas, distintas identidades, diferentes tempos, sendo que as relações por ela processadas e permitidas a colocam como lugar onde se promove uma espécie de solidariedade orgânica (SANTOS, 1994), onde se horizontalizam relações.

Entre o rio, os barcos, os portos e a feira encontramos a força de uma temporalidade que permanece, de uma dinâmica que não se perdeu, que continua existindo e proporcionando a sobrevivência de milhares de sujeitos, cujo rio é o elemento central para a reprodução da vida.

Temos, nesse sentido, uma dinâmica econômica e social que se liga ao rio, que inclui principalmente o extrativismo do açaí, da castanha e de outras frutas regionais, além da lenha. Essa dinâmica é responsável pela sobrevivência de múltiplos atores que vivem na cidade, mas principalmente daqueles que vivem em vilas e povoados à beirario e vêm cotidianamente descarregar seus produtos nos portos, seja de Baião, Cametá ou Mocajuba.

As relações econômicas nessas cidades são, portanto, mediadas pela dificuldade, pela penúria, muitas vezes pela fome, e têm no circuito inferior da economia urbana (SANTOS, 1979) um de seus principais atributos, uma vez que esses sujeitos criam dinâmicas alternativas, formas de sobrevivência singular a partir de atividades múltiplas que incluem uma diversidade de funções. São, portanto, carregadores, feirantes, produtores, atravessadores e mais uma gama de outros sujeitos subsistindo das trocas processadas a partir do rio, pelos barcos, nos portos e nas feiras. Parece mesmo que "o circuito inferior está essencialmente constituído por formas de fabricação de capital não intensivo, por serviços não modernos, geralmente abastecidos pelo nível de venda a varejo e pelo comércio em pequena escala e não moderno" (SANTOS, 2005, p. 97). 
O circuito inferior parece ainda marcar a forma de inclusão dos sujeitos que sobrevivem do rio. Mas ainda nos incomoda a definição de "inferior" e "menos moderno" para expressar o circuito econômico característico dessas cidades. Preferimos chamá-lo, sem perder de vista o grau de desigualdade em que o mesmo se forma, mas levando em conta as relações marcadas pela diferença que possibilita, de um circuito econômico alternativo, precário em termos de movimentação de valores monetários, mas extremamente rico em termos de movimentação e interação de valores sociais.

Esta permanência parece definir uma característica importante nas cidades estudadas, a constituição de uma sociedade ligada historicamente às raízes culturais locais, compondo uma região em que existe certa coesão política, posto que não encontramos grandes mobilizações em torno de projetos de fragmentação políticoterritorial. Um elemento que nos ajuda a compreender melhor essas raízes da população são os dados da tabela 4, que se mostram elucidativos, pois demonstram que a grande maioria da população destas cidades é proveniente do próprio Estado do Pará. Sendo esses dados de 2002, isso nos indica que esta região não sofreu, como outras dentro do mesmo Estado, grandes transformações a partir da intensificação da migração para a Amazônia, ocorrida principalmente a partir de 1960.

TABELA 4 - PROCEDÊNCIA DA POPULAÇÃO DOS MUNICÍPIOS DE BAIÃO, CAMETÁ E MOCAJUBA

\begin{tabular}{|l|l|l|c|c|}
\hline Municípios & População Total & \multicolumn{1}{|c|}{ Naturais do Pará } & $\begin{array}{r}\text { Naturais de } \\
\text { outros estados }\end{array}$ & $\begin{array}{c}\text { Naturais de outros } \\
\text { países }\end{array}$ \\
\hline Baião & 21.119 & $20.194(\mathbf{9 5}, \mathbf{6 2} \%)$ & 925 & - \\
\hline Cametá & 97.624 & $97.183(\mathbf{9 9 , 5 4 \% )}$ & 428 & 13 \\
\hline Mocajuba & 20.542 & $20.330(\mathbf{9 8 , 9 6 \% )}$ & 212 & - \\
\hline
\end{tabular}

Fonte: IBGE (2000)

Mas, para além dos tempos e espaços que permanecem, uma dinâmica de mudança mostra sua face nessas cidades e que procuraremos abordar a partir de agora.

A BARRAGEM, A ESTRADA, AS ANTENAS TELEFÔNICAS: MUDANÇAS... 
É progressivamente a partir da década de 1960 e principalmente de 1970, com a abertura da Transcametá (1972) e, posteriormente das outras estradas, que as cidades aqui analisadas passam a sofrer alterações significativas em suas dinâmicas.

A primeira alteração já foi mostrada e está refletida nos espaços intra-urbanos dessas cidades: é a presença, cada vez mais acentuada, do padrão rodoviário como vetor de expansão urbana. Vários são os bairros que surgem, portanto, próximos das estradas expressando uma mudança significativa nas formas de apropriação do espaço.

As tabelas 5 e 6 nos mostram alguns processos bastante significativos, principalmente no que se refere à importância que a estrada assume nas cidades analisadas.

TABELA 5 - A IMPORTÂNCIA DO RIO, HOJE E NO PASSADO

\begin{tabular}{|l|r|r|r|r|r|r|r|}
\hline & \multicolumn{2}{|c|}{ Baião } & \multicolumn{2}{c|}{ Mocajuba } & \multicolumn{2}{c|}{ Cametá } & \multicolumn{2}{c|}{ Média } \\
\hline $\begin{array}{l}\text { Importância do transporte } \\
\text { fluvial hoje }\end{array}$ & Abs. & \multicolumn{1}{c|}{$\%$} & Abs. & \multicolumn{1}{c|}{$\%$} & \multicolumn{1}{c|}{ Abs. } & \multicolumn{1}{c|}{$\%$} & $\%$ \\
\hline Muito importante & 128 & 49,33 & 185 & 71,83 & 245 & 94,08 & 71,75 \\
\hline Pouco importante & 115 & 44,17 & 67 & 25,08 & 11 & 4,33 & 24,53 \\
\hline Nenhuma importância & 17 & 6,50 & 8 & 3,08 & 4 & 1,58 & 3,72 \\
\hline Sub-total & 260 & 100,00 & 260 & 100,00 & 260 & 100,00 & 100,00 \\
\hline $\begin{array}{l}\text { Importância do transporte } \\
\text { fluvial no passado }\end{array}$ & Abs. & \multicolumn{1}{c|}{$\%$} & Abs. & $\%$ & Abs. & $\%$ & \multicolumn{1}{c|}{$\%$} \\
\hline Muito importante & 207 & 79,58 & 230 & 88,83 & 239 & 91,92 & 86,78 \\
\hline Pouco importante & 40 & 15,58 & 25 & 9,33 & 14 & 5,50 & 10,14 \\
\hline Nenhuma importância & 13 & 4,83 & 5 & 1,83 & 7 & 2,58 & 3,08 \\
\hline Sub-total & 260 & 100,00 & 260 & 100,00 & 260 & 100,00 & 100,00 \\
\hline
\end{tabular}

Fonte: Trabalho de campo, outubro/ 2008.

TABELA 6 - A IMPORTÂNCIA DA ESTRADA, HOJE E NO PASSADO

\begin{tabular}{|l|r|r|r|r|r|r|r|}
\hline & \multicolumn{2}{|c|}{ Baião } & \multicolumn{2}{c|}{ Mocajuba } & \multicolumn{2}{|c|}{ Cametá } & Média \\
\hline $\begin{array}{l}\text { Importância do transporte } \\
\text { rodoviário hoje }\end{array}$ & \multicolumn{1}{|c|}{ Abs. } & \multicolumn{1}{c|}{$\%$} & Abs. & \multicolumn{1}{c|}{$\%$} & \multicolumn{1}{c|}{ Abs. } & \multicolumn{1}{c|}{$\%$} & \multicolumn{1}{c|}{$\%$} \\
\hline Muito importante & 227 & 87,33 & 222 & 84,42 & 235 & 90,42 & 87,39 \\
\hline Pouco importante & 25 & 9,83 & 38 & 15,58 & 24 & 9,17 & 11,53 \\
\hline Nenhuma importância & 8 & 2,83 & 0 & 0,00 & 1 & 0,42 & 1,08 \\
\hline Sub-total & 260 & 100,00 & 260 & 100,00 & 260 & 100,00 & 100,00 \\
\hline $\begin{array}{l}\text { Importância do transporte } \\
\text { rodoviário no passado }\end{array}$ & Abs. & $\%$ & Abs. & $\%$ & Abs. & \multicolumn{1}{c|}{$\%$} & $\%$ \\
\hline Muito importante & 36 & 13,50 & 79 & 30,58 & 118 & 46,25 & 30,11 \\
\hline Pouco importante & 158 & 61,42 & 127 & 48,58 & 97 & 37,42 & 49,14 \\
\hline Nenhuma importância & 66 & 25,08 & 54 & 20,83 & 45 & 16,33 & 20,75 \\
\hline Sub-total & 260 & 100,00 & 260 & 100,00 & 260 & 100,00 & 100,00 \\
\hline
\end{tabular}

Fonte: Trabalho de campo, outubro/2008. 
Esses dados nos mostram que o transporte rodoviário vem ganhando cada vez mais espaço, respectivamente, em Baião, Mocajuba e Cametá. Se o rio aparece como muito importante no passado, com $86,78 \%$ na média das respostas nas três cidades, ele perde um pouco de sua importância, uma vez que hoje ele é muito importante para $71,75 \%$ na média das cidades. Por outro lado, a estrada que no passado era pouco importante para $49,14 \%$ dos sujeitos, hoje é muito importante para $87,39 \%$ da média da população pesquisada nas três cidades.

Logicamente que se analisarmos cada cidade em específico perceberemos algumas variações que demonstram que a dinâmica de transformações são maiores nas cidades de Baião e Mocajuba e menores em Cametá. Mas se considerarmos que para 90,42\% da população ouvida em Cametá o transporte rodoviário é importante hoje, não podemos pensar que esta cidade está fora desse processo de transformação.

Por outro lado, é importante destacar que, do ponto de vista das escalas, o rio ganha mais importância no interior da escala sub-regional (tabela 7) e é cada vez menos importante na escala regional (tabela 8), especialmente se considerarmos os deslocamentos em direção a Belém ou vice-versa, feito cada vez mais por meio da rodovia.

TABELA 7 - DESLOCAMENTO NO BAIXO TOCANTINS

\begin{tabular}{|l|r|r|r|r|r|r|r|}
\hline & \multicolumn{2}{|c|}{ Baião } & \multicolumn{2}{c|}{ Cametá } & \multicolumn{2}{c|}{ Mocajuba } & Média \\
\hline Deslocamento & Abs. & \multicolumn{1}{|c|}{ \% } & Abs. & \% & Abs. & \multicolumn{1}{c|}{$\%$} & $\%$ \\
\hline Bicicleta & & & & & & & \\
\hline Moto & & 0,00 & 1 & 0,38 & 4 & 1,54 & 0,64 \\
\hline Carro/ônibus/van & 3 & 1,15 & 3 & 1,15 & 21 & 8,08 & 3,46 \\
\hline Barco/canoa & 128 & 49,23 & 38 & 14,62 & 93 & 35,76 & 33,20 \\
\hline $\begin{array}{l}\text { Barco/canoa/carro/moto/ } \\
\text { ônibus }\end{array}$ & 77 & 29,62 & 155 & 59,62 & 106 & 40,77 & 43,34 \\
\hline Outros & 42 & 16,15 & 46 & 17,69 & 36 & 13,85 & 15,90 \\
\hline Não vai & 2 & 0,77 & 0 & 0 & - & - & 0,26 \\
\hline Sub-total & 8 & 3,08 & 17 & 6,54 & - & - & 3,21 \\
\hline
\end{tabular}

Fonte: Trabalho de campo, outubro/2008. 
TABELA 8 - DESLOCAMENTO PARA BELÉM

\begin{tabular}{|c|c|c|c|c|c|c|c|}
\hline & \multicolumn{2}{|c|}{ Baião } & \multicolumn{2}{|c|}{ Cametá } & \multicolumn{2}{|c|}{ Mocajuba } & Média \\
\hline Deslocamento & Abs. & $\%$ & Abs. & $\%$ & Abs & $\%$ & $\%$ \\
\hline Carro/ônibus/van & 220 & 84,62 & 51,00 & 19,62 & 194 & 74,62 & 59,62 \\
\hline Barco/canoa & 14 & 5,38 & 88,00 & 33,85 & 45 & 17,30 & 18,84 \\
\hline $\begin{array}{l}\text { Barco/canoa/carro/moto/ } \\
\text { onibus }\end{array}$ & 22 & 8,46 & 118,00 & 45,38 & 21 & 8,08 & 20,64 \\
\hline Não vai & 4 & 1,54 & 3 & 1,15 & - & - & 0,90 \\
\hline Sub-total & 260 & 100 & 260 & 100 & 260 & 100 & 100 \\
\hline
\end{tabular}

Fonte: Trabalho de campo, outubro/2008.

Se considerarmos os dados de circulação entre as cidades, vilas e comunidades do Baixo Tocantins ainda o rio e a estrada aparecem com a mesma importância para os fluxos, mas se observarmos o deslocamento das cidades analisadas para Belém é significativa a média dos sujeitos ouvidos das três realidades que afirmam que usam o transporte rodoviário para o deslocamento até a capital do Estado.

Mas não é apenas a estrada a causadora das mudanças, a barragem do rio Tocantins edificada pela UHT, alterou sobremaneira a vida da população das cidades à jusante da usina, sendo que esta alteração foi, logicamente, progressivamente maior quanto mais próximo da barragem, neste caso, em ordem decrescente de mudanças: Baião, Mocajuba e Cametá. Tais mudanças consistem principalmente na diminuição dos peixes existentes no rio, o que ocasiona sérios problemas para os pescadores da região e para um conjunto de populações que usa o rio principalmente como fonte de recursos.

Quando perguntamos se o rio estava poluído ou apresentava problemas, $76 \%$ dos sujeitos pesquisados das três cidades afirmaram que sim e a tabela 9 demonstra os motivos indicados para esta poluição e/ou problemas. 
TABELA 9 - FATORES QUE INFLUENCIAM NA POLUIÇÃO E NA EXISTÊNCIA DE PROBLEMAS NO RIO TOCANTINS

\begin{tabular}{|l|r|r|r|r|r|r|r|}
\hline & \multicolumn{2}{|c|}{ Baião } & \multicolumn{2}{c|}{ Mocajuba } & \multicolumn{2}{c|}{ Cametá } & \multicolumn{2}{c|}{ Média } \\
\hline Fatores poluentes & \multicolumn{1}{|c|}{ Abs. } & \multicolumn{1}{c|}{$\%$} & Abs. & \multicolumn{1}{c|}{$\%$} & Abs. & \multicolumn{1}{c|}{$\%$} & \% \\
\hline Barragem & 71 & 27,08 & 52 & 20,25 & 42 & 20,25 & 48,72 \\
\hline Lixo jogado no rio & 102 & 39,50 & 139 & 53,33 & 94 & 53,33 & 22,28 \\
\hline Não está poluído & 68 & 26,33 & 53 & 20,25 & 53 & 20,25 & 5,22 \\
\hline Esgoto/fossa & 9 & 3,33 & 16 & 6,17 & 16 & 6,17 & 0,92 \\
\hline Não sabe & 7 & 2,75 & 0 & 0,00 & 0 & 0,00 & 0,33 \\
\hline Outros & 3 & 1,00 & 0 & 0,00 & & 0,00 & 100,00 \\
\hline Sub-total & 260 & 100,00 & 260 & 100,00 & 260 & 100,00 &
\end{tabular}

Fonte: Trabalho de campo, outubro/2008.

A partir da tabela percebemos que a expressiva maioria das respostas (48, $78 \%$ ) indica que o rio está poluído pelo lixo nele jogado, mas 22,53\% das respostas na média das três cidades apontam a barragem como fator poluente ou responsável por problemas; fato este que reporta as implicações locais advindas com a construção da Usina Hidrelétrica de Tucuruí. Vale dizer que estas respostas que apontam a barragem sempre vinham junto com explicações que mostravam o conjunto de alterações na vida econômica, social e cultural destas cidades após a construção da UHT ${ }^{5}$.

Outro vetor de transformação das cidades é a expansão do cultivo da pimenta do reino, principalmente a partir da década de 1970, acompanhando as rodovias PA-151 (Barcarena-Baião) e PA-156 (Transcametá). A expansão do cultivo desse produto, além de significar uma expansão urbana no vetor das estradas e vicinais, também passa, no período mais recente, a inserir a região em circuitos econômicos extra-locais reproduzindo uma racionalidade mercadológica até então pouco vista nas cidades analisadas, inclusive tornando-se a principal cultura agrícola desses municípios e a maior área plantada de agricultura permanente.

Como expressão do cultivo da pimenta do reino, observamos várias vilas e povoados localizados próximos ou nas margens das estradas se especializarem na

\footnotetext{
${ }^{5}$ Destacam-se elementos como alteração na cor da água, presença de limo antes não existente, rarefação da quantidade e das espécies de pescado, submersão da floresta, alteração da qualidade da água devido ao uso de elementos tóxicos quando do desmatamento para formação do lago de Tucuruí, dentre outros.
} 
produção desta cultura agrícola; produção esta que é vendida a grandes atravessadores (chamados barões da pimenta) por um preço baixo, ilustrando uma relação desigual que muito ajuda na compreensão do grau de concentração de renda visualizado nas três realidades observadas.

Além da rodovia e dos novos fluxos econômicos, as redes de telecomunicação, seja em termos de emissoras e/ou repetidoras de TV, seja em termos de telefonia fixa ou móvel, também deixam suas marcas impressas no cotidiano dessas cidades. Isso nos lembra a descrição de Oliveira e Schor (2008) na qual as torres da igreja e as antenas telefônicas aparecem hoje como a expressão maior da paisagem na chegada às pequenas cidades da Amazônia.

Como dito anteriormente, não é apenas uma esfera técnica que se difunde pelo território alterando atividades econômicas, formas de circulação, facilitando a reprodução e circulação do capital, mas também uma esfera de valores que se dissemina e deixa suas marcas no modo de vida dos sujeitos, que cada vez mais precisam de celulares para se comunicar, da televisão para se divertir e do consumo para serem felizes.

CIDADES HÍBRIDAS FLÚVIO-RODOVIÁRIAS: MUDANÇAS E PERMANÊNCIAS À JUSANTE DA UHT

Chegamos pelos meandros do rio e pelas curvas das estradas a cidades que se animam por ritmos distintos, mas contraditoriamente articulados. Cidades que ganham vida por temporalidades não contemporâneas, mas coexistentes; cidades de várias cores, do verde do rio ao vermelho da piçarra; de vários sabores, do peixe fresco à carne enlatada; de vários sons, do samba de cacete ao tecnobrega; de vários sonhos, do barco novo ao carro novo; de vários objetos, da torre da igreja às antenas telefônicas; de várias etnias, do índio ao homem urbano; enfim, cidades híbridas de objetos, relações e significados.

Temos, nesse sentido, por um lado, uma dinâmica econômica que se liga ao rio, que inclui principalmente o extrativismo do açaí, da castanha, do cacau, da lenha e de toda sorte de frutas regionais; dinâmica esta que é responsável pela sobrevivência de 
múltiplos atores que vivem nas cidades, nas vilas, nos povoados que têm os portos e a feira como espaços fundamentais de sobrevivência. Por outro lado, temos o extrativismo de madeira em tora, realizado por madeireiros, muitas vezes de forma irregular, não tendo uma racionalidade no manejo da floresta e não gerando divisas aos municípios, ou o plantio da pimenta do reino, geralmente obedecendo aos eixos de circulação rodoviários.

Os dados que seguem (tabela 10) demonstram muito bem a presença do rio e das estradas no cotidiano dos sujeitos das realidades estudadas.

TABELA 10 - FORMA DE DESLOCAMENTO NO INTERIOR DOS MUNICÍPIOS

\begin{tabular}{|c|c|c|c|c|c|c|c|}
\hline & \multicolumn{2}{|c|}{ Baião } & \multicolumn{2}{|c|}{ Mocajuba } & \multicolumn{2}{|c|}{ Cametá } & \multirow{2}{*}{$\begin{array}{c}\text { Média } \\
\% \\
\end{array}$} \\
\hline município & Abs. & $\%$ & Abs. & $\%$ & Abs. & $\%$ & \\
\hline A pé & 5 & 1,92 & 9 & 3,50 & 1 & 0,33 & 1,92 \\
\hline Bicicleta & 26 & 10,08 & 17 & 6,67 & 11 & 4,50 & 7,08 \\
\hline Moto & 25 & 9,25 & 54 & 20,58 & 18 & 7,17 & 12,33 \\
\hline Carro/ônibus/van & 69 & 26,33 & 62 & 23,08 & 43 & 17,17 & 22,19 \\
\hline Barco/canoa & 74 & 29,08 & 0 & 0,00 & 132 & 50,17 & 26,42 \\
\hline $\begin{array}{l}\text { Barco/canoa/carro/ } \\
\text { moto/ônibus/van }\end{array}$ & 48 & 18,92 & 61 & 24,42 & 46 & 17,25 & 20,19 \\
\hline Outros & 4 & 1,33 & 0 & 0,00 & 3 & 1,25 & 0,86 \\
\hline Não vai & 9 & 3,08 & 53 & 20,41 & 6 & 2,17 & 8,55 \\
\hline Sub-total & 260 & 100,00 & 260 & 100,00 & 260 & 100,00 & 100,00 \\
\hline
\end{tabular}

Fonte: Trabalho de campo, outubro/2008.

Há, como se depreende dos dados, um uso misto dos meios de transporte no que se refere ao deslocamento no interior dos municípios. Se analisarmos os mesmos, veremos que $26,42 \%$ dos sujeitos pesquisados nas três cidades responderam que usam apenas barco e/ou canoa para se deslocarem, enquanto, associando os números de carro/ônibus/van com moto, observamos que 34,52\% destes sujeitos só utilizam estes meios de transporte para se deslocarem, sendo, ainda, que $20,19 \%$ dos mesmos usam conjuntamente barco/canoa e carro/ônibus/van/moto.

Se entendermos que o deslocamento no interior do município compõe o cotidiano dos sujeitos das realidades estudadas, uma vez que esses deslocamentos são motivados pelo trabalho, pelo lazer, pela visita aos parentes, dentre outros motivos, 
podemos concluir existir um uso literalmente misto do rio e das estradas como eixos de circulação.

Um dado mais característico ainda coletado através da pesquisa de campo se encontra sistematizado na tabela 11:

TABELA 11 - EQUIPAMENTOS URBANOS IMPORTANTES PARA USO DA POPULAÇÃO

\begin{tabular}{|l|r|r|r|r|r|r|r|}
\hline & \multicolumn{2}{|c|}{ Baião } & \multicolumn{2}{|c|}{ Mocajuba } & \multicolumn{2}{c|}{ Cametá } & Média \\
\hline Equipamentos importantes & Abs. & \multicolumn{1}{c|}{$\%$} & Abs. & \multicolumn{1}{c|}{$\%$} & \multicolumn{1}{c|}{ Abs. } & \multicolumn{1}{c|}{$\%$} & $\%$ \\
\hline Portos e trapiches & 62 & 23,92 & 44 & 17,50 & 196 & 75,00 & 38,81 \\
\hline Terminal rodoviário & 154 & 59,50 & 123 & 45,92 & 28 & 10,92 & 38,78 \\
\hline Aeroporto & 11 & 4,50 & 7 & 2,83 & 7 & 2,92 & 3,42 \\
\hline $\begin{array}{l}\text { Portos e trapiches/ } \\
\text { terminal rodoviário }\end{array}$ & 33 & 12,08 & 86 & 20,42 & 26 & 10,00 & 14,17 \\
\hline $\begin{array}{l}\text { Nenhum dos } \\
\text { equipamentos acima }\end{array}$ & 0 & 0,00 & 0 & 0,00 & 3 & 1,17 & 0,39 \\
\hline Sub-total & 260 & 100,00 & 260 & 100,00 & 260 & 100,00 & \\
\hline
\end{tabular}

Fonte: Trabalho de campo, outubro/2008.

Na média das três realidades, $38,81 \%$ dos sujeitos responderam que os portos e trapiches são os equipamentos mais importantes, enquanto também $38,78 \%$ dos mesmos afirmam ser o terminal rodoviário o equipamento mais essencial, sendo que $14,17 \%$ ainda afirmam que os portos e trapiches e o terminal rodoviário possuem a mesma importância.

Logicamente que existe uma grande diferença nos dados se considerarmos cada realidade em específico. Baião e Mocajuba, localizadas na margem direita do Tocantins parecem, então, sofrerem um processo de mudança muito maior que Cametá, pela maior facilidade de articulação a Belém por meio da rodovia. Mas se entendermos que as duas primeiras cidades estão ligadas de maneira muito forte à última, principalmente porque dependem desta em termos de serviços e também muitas vezes em termos de comércio, se percebermos, ainda, que boa parte da circulação, seja através do rio, seja através da estrada, das duas primeiras cidades se direciona a Cametá, temos de convir que os dados são muito expressivos.

Enquanto formações econômico-sociais do Baixo Tocantins, as cidades aqui consideradas para análise se apresentam enquanto híbridas no que se refere aos processos ligados ao rio e à estrada, às dinâmicas desenroladas através dos fluxos fluviais e às motivadas pelos fluxos rodoviários. Mas os termos da hibridização dessas 
cidades não estão apenas na dinâmica até aqui mostrada, expressam-se, também, na forma de relação entre os sujeitos, que caminha entre interações permeadas por uma hierarquia social cimentada pela notabilidade e interações dinamizadas por uma lógica econômica do mercado, portanto, por interações (mercado)lógicas.

Conforme mencionado anteriormente, Santos (1993) apontava que no Brasil moderno as "cidades dos notáveis" tendem a ser substituídas pelas "cidades econômicas". Nestas, figuras como o engenheiro agrônomo, o gerente de banco, os técnicos agrícolas especializados, dentre outros, tendem a substituir em importância figuras notáveis como o vigário, a professora primária, o juiz de direito. No caso da Amazônia, em especial da Amazônia aqui focalizada, parece que esta afirmação deve ser relativizada. As "cidades dos notáveis" permanecem ao lado das "cidades econômicas", tudo isso na mesma cidade.

A notoriedade do vigário, da professora primária, do trabalhador dos correios, do juiz de direito convive com a notoriedade do gerente do banco, do engenheiro agrônomo, dos professores universitários, dos técnicos agrícolas. Mas isso se reproduz conjuntamente com uma dinâmica de relações econômicas que inserem muitas vezes tais cidades no processo de reprodução do capital. O que falar da pimenta do reino e seus grandes atravessadores? Ou do carnaval de Cametá que, dos mais tradicionais do Estado, transformou-se em uma grande micareta ao estilo "carnaval baiano"?

Mas, afora os processos de reprodução ampliada do capital que existem, ainda assim uma dinâmica do circuito inferior da economia anima a vida da maioria dos sujeitos das realidades observadas. Nesse sentido, essas cidades além de híbridas são pequenas e locais, uma vez que, nos termos de Santos (2004), apresentam forte solidariedade orgânica e pouca solidariedade organizacional, o que nos leva a crer que existe um predomínio das horizontalidades em vez das verticalidades nas mesmas ${ }^{6}$.

\footnotetext{
${ }^{6}$ Os atributos das espacialidades, segundo Santos (1994), tendem a se tornar menos rígidos do ponto de vista da continuidade e da contigüidade absoluta, posto que as solidariedades organizacionais de hoje tendem a substituir as solidariedades orgânicas de outrora. Em outros termos, os nexos de energia são substituídos por nexos de informação, em que se definem recortes horizontais - espaços contínuos, formados de partes agregadas, condição e resultado das relações de produção propriamente dita -, e verticais - pontos separados uns dos outros que asseguram o funcionamento global da sociedade e da economia, e que resultam das novas necessidades de intercâmbio e de regulação.
} 
Portanto, elas aparecem como referência de serviços e comércios para as populações locais em vez de base logística para grandes projetos, não se mostrando como enclaves urbanos, mas principalmente como localidades centrais da sub-região onde se localizam. São também importantes centros articuladores dos movimentos sociais ligados à realidade do baixo Tocantins. Não sem razão observarmos múltiplos movimentos emergindo nessas realidades, como o Movimento dos Atingidos por Barragem (MAB), as Colônias de Pescadores e organizações quilombolas.

As experiências sociais nessas cidades, nesse sentido, desenham alternativas múltiplas, sejam estas econômicas, políticas ou culturais que não podem ser deixadas à margem só porque são produzidas à margem. Essas experiências prolongam o presente e atualizam a história "na qual tudo que é passado (em seu tempo) pode adquirir um grau mais alto de atualidade do que no próprio momento de sua existência" (BENJAMIN, 2006, p. 939).

Entre grandes objetos espaciais, entre o rio e a estrada, entre as relações permeadas pela notabilidade e pelo mercado, as cidades de Cametá, Mocajuba e Baião são espacialidades dinamizadas por tempos sociais não contemporâneos, mas coexistentes, produto e condição para uma multiplicidade de trajetórias e identidades.

Diante desses argumentos devemos concordar e trazer para o debate as considerações de Boaventura de Souza Santos para quem

[...] o mais importante no mundo de hoje é que tanta experiência social não fique desperdiçada, porque ocorre em lugares remotos. Experiências muito locais, não muito conhecidas nem legitimadas pelas ciências sociais hegemônicas, são hostilizadas pelos meios de comunicação social, e por isso têm permanecido invisíveis, desacreditadas. A meu ver o primeiro desafio é enfrentar esse desperdício de experiências sociais que é o mundo (SOUZA SANTOS, 2007, p.23-24),

\section{ALGUMAS PALAVRAS FINAIS}

As cidades até aqui analisadas apresentam-se, em última análise, e tomando como inspiração a leitura de espaço de Massey e Keynes (2004) e Massey (2008), como formações sócio-espaciais produzidas por inter-relações e, ao mesmo tempo, 
condicionantes e abrigo para a multiplicidade de tempos distintos, de identidades diversas e de espacialidades (des)encontradas. Isso as define como lugares da alteridade em constante devir. São, também, reflexo de múltiplos contextos, de variadas formas de uso do tempo e do espaço, para não dizer que são simultaneidade, movimento e dinamismo, expressando processos de longa duração que permanecem frente aos diferentes contextos, mas também expressando processos que se modificam e se transformam em confronto com novas dinâmicas que chegam sem pedir licença.

Cidades híbridas em termos de forma e conteúdo, Baião, Cametá e Mocajuba expõem experiências sociais marcadas por tensões entre várias lógicas. São produzidas por relações permeadas por uma hierarquia social recheada de simbolismos, ao mesmo tempo condicionantes para o enriquecimento de agentes econômicos. São cidades do rio e da estrada, mas acima de tudo são lugares onde as relações se horizontalizam, o que as desenha como localidades centrais para a região.

Tal centralidade, diga-se de passagem, não advém da modernização da economia das cidades estudadas, mas do peso da experiência social processada por e a partir das mesmas. São hibridas, mas desempenham uma importância singular para seus entornos imediatos e para a microrregião banhada pelo baixo curso do rio Tocantins, oficialmente definida como a microrregião de Cametá.

Algumas conclusões decorrem desta análise. A primeira delas é que devemos considerar a importância das cidades aqui analisadas não por um apelo saudosista, mas pelo papel que desempenham para um conjunto de grupos sociais que delas dependem, seja do ponto de vista material, seja do ponto de vista simbólico. Daí tornar-se necessária a compreensão das mesmas enquanto espaços de (sobre)vivência, onde desigualdade e diferença são elementos co-constitutivos, onde a sobrevida caminha ao lado da vida, onde a dinâmica de sobreviver permite o viver e as trocas pressupõem encontros.

A segunda conseqüência da análise é a consideração de que essas cidades apresentam forte solidariedade orgânica, nos termos definidos por Santos (1994) e em contraponto àquelas cidades-empresa ou company towns, que se caracterizam 
notadamente pela forte solidariedade organizacional. Em sendo cidades organicamente solidárias com seu entorno imediato, e a partir da inspiração dada pela tipologia de cidades proposta por Schor e Costa (2007), podemos considerar Cametá, em uma escala microrregional, e Baião e Mocajuba, em uma escala local, como cidades de responsabilidade territorial, que exercem diversos papéis importantes para o espaço que lhe é imediato, desempenhando funções institucionais imprescindíveis (principalmente para o caso de Cametá), tendo essa importância sido construída pelos seus processos históricos de formação territorial. Essa forma de compreensão faz com que pensemos essas cidades como prioridades políticas.

A terceira conseqüência diz respeito ao fato que a alternativa política para essas cidades está expressa na própria experiência social dos sujeitos que as usam e produzem cotidianamente. Nesse sentido, é preciso que não mais desperdicemos essas experiências sociais para que consigamos construir instrumentos de planejamento e gestão realmente alinhados a tais realidades.

Uma quarta e última conseqüência diz respeito à consideração dessas cidades como formações sócio-espaciais híbridas. Isso nos leva a entendê-las como produto e condição para a existência da multiplicidade e como dinâmicas, o que nos encaminha a pensar políticas não essencialistas para as mesmas, ou seja, políticas que não enclausurem essas cidades a uma beira de rio ou de estrada, nem as congele a partir de modelos frios e sem vida. É preciso que a política mergulhe na dinamicidade de tais realidades e não se prenda a modelos esquemáticos, como os instrumentos previstos no Estatuto da Cidade, no sentido de construir ações cada vez mais alinhadas às demandas locais, incorporando toda a potencialidade política expressa em movimentos sociais, associações, colônia de pescadores, entre outros.

É preciso dar maior visibilidade a experiência e, assim, dar mais importância às cidades aqui analisadas, pois muito mais do que enclaves territoriais, ou cidades organizacionalmente solidárias, com fortes verticalidades econômicas, que não conseguem enraizar o desenvolvimento, tratam-se de formações sócio-espaciais que horizontalizam relações, permitem a sobrevivência de milhares de sujeitos, são ricas em experiências sociais, sejam estas econômicas, políticas e/ou culturais. Ensinam-nos, 
portanto, que um novo caminho é possível, pois gestam em seu cotidiano novas formas e possibilidades de mudanças.

\section{AMONG RIVERS, HIGHWAYS AND GREAT PROJECTS: CHANGES AND PERMANENCES IN URBAN REALITIES OF THE LOW TOCANTINS (PARÁ)}

ABSTRACT: A reflection on the changes and continuities of riverside cities in the Amazon is of particular importance, because it allows: to analyze the socio-spatial profile of those cities that are considered as traditional, to discuss parameters of political thinking to their development, and also, to problematize what is the right to the city in them. In this way, we take the game between the regional particularities and singularities of these cities as a starting point for the exercise of planning and management that incorporate specific local demands and also taking in consideration, consequently, its main socio-spatial attributes. In order to undertake this discussion, we take into account the peculiarities and particularities of the socio-spatial realities of three cities in the Northeast of Pará: Baião, Mocajuba and Cametá. Located at South of Tocantins, these cities are situated between two large economic projects, the Tucuruí's Hydroeletric Power Station, at the city of Tucuruí, and Albras-Alunorte's Complex, at the city of Barcarena. From the conditions of traditional coastal towns and the new network components installed more recently in the sub-region of which they form, we are seeking to discuss the processes of changes and continuities in terms of socio-spacial point of view related to them.

KEY-WORDS: Riverside cities, Lower Tocantins, Hybrid Cities, Rivers, Roads.

\section{REFERÊNCIAS}

BENJAMIN, W. Passagens. Belo Horizonte: Editora UFMG; São Paulo: Imprensa Oficial do Estado de São Paulo, 2006.

BRITO, D. C. Modernização de superfície: Estado e desenvolvimento na Amazônia. Belém: NAEA/UFPA, 2001.

CORRÊA, R. L. A periodização da rede urbana na Amazônia. Revista Brasileira de Geografia, Rio de Janeiro, v. 49, n. 03, p. 39-68, jul./set. 1987. 
D'ARAÚJO, M. C. Amazônia e desenvolvimento à luz das políticas governamentais: a experiência dos anos 50. Revista brasileira de Ciências Sociais, n. 9, ano 7, p.41-55, jun. 1992.

DI PAOLO, P. Cabanagem: a revolução popular da Amazônia. Belém: Conselho de Cultura, 1985.

IBGE. Instituto Brasileiro de Geografia e Estatística. Sinopse Preliminar do Censo

Demográfico 2000. Rio de janeiro: IBGE, 2000.

LEFEBVRE, H. O direito à cidade. São Paulo: Editora Moraes, 2001.

MASSEY, D.; KEYNES, M. Filosofia política da espacialidade: algumas considerações. Geographia, n. 12. Niterói, RJ, UFF/EGG, 2004, p.7-23.

MASSEY, D. Pelo espaço: uma nova política da espacialidade. Rio de Janeiro: Bertrand Brasil, 2008.

MARTINS, J. S. Fronteira: degradação do outro nos confins do humano. São Paulo: Hucitec, 1997.

O Liberal, 08/05/2005, Cad. Atualidades, p. 3.

OLIVEIRA, J. A; SCHOR, T. Das cidades da natureza à natureza das cidades. In: TRINDADE JR., S. C.; TAVARES, M. G. C. (Orgs.). Cidades ribeirinhas na Amazônia: mudanças e permanências. Belém: EDUFPA, 2008. p. 15-26

POMPEU, J. D. P.. Evolução territorial e urbana do Município de Cametá. Cametá: Novo Tempo, 2002.

PREFEITURA MUNICIPAL DE BAIÃO. Baião: bicentenário de fundação. Baião: PMB, 1979.

SANTOS, M. O espaço dividido: os dois circuitos da economia urbana dos países subdesenvolvidos. Rio de Janeiro: F.Alves, 1979. (Coleção Ciências Sociais).

. A urbanização brasileira. São Paulo: HUCITEC, 1993.

. Técnica, espaço, tempo: globalização e meio técnico-científico informacional.

São Paulo: Hucitec, 1994.

Os grandes projetos: sistema de ação e dinâmica espacial. In: CASTRO, E.; MOURA, E.; MAIA, M. L. S. (Orgs.). Industrialização e grandes projetos: desorganização e reorganização do espaço. Belém: EDUFPA, 1995. p.13-20.

A natureza do espaço: técnica e tempo, razão e emoção. São Paulo: Edusp, 2004.

Da totalidade ao lugar. São Paulo: EDUSP, 2005.

SCHOR, T.; COSTA, D. P. Rede urbana na Amazônia dos grandes rios: uma tipologia para as cidades na calha do rio Solimões - Amazonas - AM. In: Simpósio Nacional de Geografia Urbana, X, 2007, Florianópolis, Anais... Florianópolis: Associação dos Geógrafos Brasileiros, 2007.

SEPOF. Secretaria de Estado de Planejamento, Orçamento e Finanças. Estatística dos municípios. Belém: SEPOF, 2006.

SILVA BRUNO, E. História do Brasil: geral e regional - Amazônia. São Paulo: Cultrix, 1966.

SOUZA SANTOS, B. Renovar a teoria crítica e reinventar a emancipação social. São Paulo: Boitempo, 2007.

TRINDADE JR, S. C.; SILVA, M. A. P; AMARAL, M. D. B. Das "janelas" às "portas" para os rios: compreendendo as cidades ribeirinhas na Amazônia. In: TRINDADE JR., S. C.; 
TAVARES, M. G. C. (Orgs.). Cidades ribeirinhas na Amazônia: mudanças e permanências. Belém: EDUFPA, 2008. p. 27-47.

WEINSTEIN, B. A borracha na Amazônia: expansão e decadência, 1850-1920. São Paulo: HUCITEC, 1993. 